University of Vermont

UVM ScholarWorks

University Libraries Faculty and Staff

Publications

University Libraries

3-14-2018

\title{
Bibliometric Analysis of Scholarly Publications on the Zika Virus, 1952-2016
}

Frances A. Delwiche

University of Vermont, fdelwich@uvm.edu

Follow this and additional works at: https://scholarworks.uvm.edu/libfacpub

Part of the Congenital, Hereditary, and Neonatal Diseases and Abnormalities Commons, Infectious

Disease Commons, Medical Microbiology Commons, Virus Diseases Commons, and the Viruses

Commons

Recommended Citation

Delwiche FA. Bibliometric Analysis of Scholarly Publications on the Zika Virus, 1952-2016. Science \& Technology Libraries. 2018. doi: 10.1080/0194262X.2018.1431589.

This Article is brought to you for free and open access by the University Libraries at UVM ScholarWorks. It has been accepted for inclusion in University Libraries Faculty and Staff Publications by an authorized administrator of UVM ScholarWorks. For more information, please contact scholarworks@uvm.edu. 


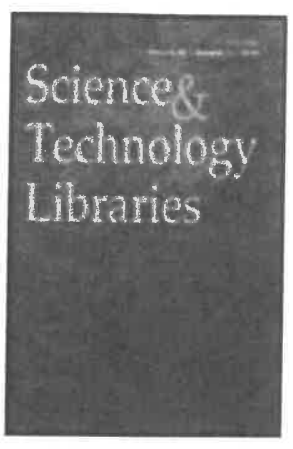

Bibliometric Analysis of Scholarly Publications on the Zika Virus, 1952-2016

\begin{tabular}{|r|l|}
\hline Journal: & Science \& Technology Libraries \\
\hline Manuscript ID & WSTL-2017-0039.R1 \\
\hline Manuscript Type: & Original Article \\
\hline Keywords: & Bibliometrics, Scholarly Literature, Zika Virus, ZIKV, Journal Productivity \\
\hline
\end{tabular}

\section{SCHOLARONE ${ }^{m}$ \\ Manuscripts}



Bibliometric Analysis of Zika literature

\title{
Bibliometric Analysis of Scholarly Publications on the Zika Virus, 1952-2016
}

\begin{abstract}
The 2015-2016 epidemic in the Americas caused by the Zika Virus (ZIKV) triggered a dramatic increase in the number of scholarly publications on this topic. In an effort to understand and characterize this body of literature, a bibliometric study was conducted on all articles found in PubMed that were published on the Zika virus between 1952 and 2016. Study parameters included publication date, source journal, subject and category of source journal, and country of first author. The data was frequency-ranked, enabling identification of the most highly productive journal titles, subject areas, and countries. The study concluded with a comparison between the number of opinion pieces versus research articles published on ZIKV and five other emerging infectious diseases. Results of the study will be of interest to students, researchers, and librarians \& information science professionals, and will serve as a baseline for subsequent analyses.
\end{abstract}

\author{
Keywords: \\ Bibliometrics \\ Journal Productivity \\ Scholarly Literature \\ Zika Virus \\ ZIKV
}




\section{Bibliometric Analysis of Scholarly Publications on the Zika Virus, 1952-2016}

\section{Introduction}

When the Zika Virus (ZIKV) was first identified in 1947 during a sylvatic yellow fever study in Uganda (Dick, Kitchen, and Haddow 1952, Zhou et al. 2016), few could have anticipated that nearly seventy years later it would trigger an epidemic resulting in over 810,000 cases throughout the western hemisphere (Pan American Health Organization 2017).

ZIKV is a mosquito-borne (+)ssRNA virus belonging to the family Flaviviridae, which includes the yellow fever, dengue, Japanese encephalitis, and West Nile viruses (Oxford, Kellam, and Collier 2016). The virus was initially thought to be relatively benign, causing only sporadic cases across Africa and Asia in the sixty years following its discovery (Vasconcelos and Calisher 2016). During that time, limited research was conducted on ZIKV, much of which focused on its serologic and taxonomic relationships with other arthropod-borne viruses.

In 2007, the first substantial outbreak of ZIKV occurred on Yap Island in the Federated States of Micronesia, producing illness in over 900 people (Duffy et al. 2009). In 2013-2014, a far larger outbreak occurred in French Polynesia that sickened 28,000 people, closely followed by outbreaks in New Caledonia, the Cook Islands, and Easter Island (Musso, Nilles, and Cao-Lormeau 2014). In early 2015, ZIKV emerged in the western hemisphere, with hundreds of cases cropping up in northeast Brazil, accompanied by a troubling spike in the incidence of microcephaly among newborns and Guillain-Barre Syndrome. Over the course of the next eighteen months, the number of suspected and confirmed cases of ZIKV in the Americas increased dramatically, triggering a concomitant upsurge in the number of scholarly journal articles published on the topic.

In an effort to characterize and understand this rapidly growing body of literature, the field of bibliometrics was consulted. Bibliometrics is the study of the scientific literature of a given field through 


\section{Bibliometric Analysis of Zika literature}

the use of methods such as descriptive analyses, measures of author and journal productivity, and identification of scientific collaborations and research networks (Andres 2009). Bibliometric studies have been conducted in the humanities, social sciences, mathematics, engineering, physical sciences, and life sciences, including medicine and nursing. Several viral infectious diseases have been the subject of bibliometric studies, including Chikungunya (Vera-Polania et al.), Dengue (Zyoud 2016), Ebola (CruzCalderon 2015, Garg and Kumar 2016), and Oropouche (Culquichicon et al. 2017). Bibliometrics have been widely used in library \& information science, especially for collection management and resource access (Schloman 1997, Lascar and Mendelsohn 2001, Davis 2002, Crawley-Low 2006, Rethlefsen and Livinski 2013).

To date, four bibliometric studies on ZIKV have been identified. A letter-to-the-editor published in early 2016 examined 325 articles published before June 2015, as obtained from three databases: Science Citation Index, Scopus, and GoPubMed (Martinez-Pulgarin et al. 2016). Among other parameters, the article reported on the top countries publishing on ZIKV, correlating those findings to major research networks. Another study published at about the same time examined 242 articles on ZIKV published before January 2016, which were obtained from five databases: LILACS (Literatura Latino Americana em Ciências da Saúde), PubMed, SciELO (Scientific Electronic Library Online), Scopus, and Web of Knowledge (Martins 2016). Study parameters included the number of articles from each database, a publication timeline, a frequency-ranked journal list, and the number of articles by topic. This was followed by a "short communication" that examined 567 articles on ZIKV found in Scopus at the end of March 2016 (Singh 2016). This study examined authorship patterns and author productivity using Lotka's Law, and the distribution of source journals using Bradford's Law of Scattering. The five most productive journals were identified, as well as the most productive countries. In January 2017, a "viewpoint" article was published describing the ZIKV literature found in Web of Science and Scopus from 1952 through August 2016 (Albuquerque et al. 2017). This article provided information on the total 
number of articles from each database, countries of publication, publication types, research areas, and patent applications. Finally, though not a bibliometric study, it is worth mentioning the 2016 scoping review by Waddell and Greig that analyzed 233 primary research studies published on ZIKV as of March 2016 (Waddell and Greig 2016).

\section{Objective}

The aim of this study was to conduct a bibliometric analysis of the scholarly journal literature on ZIKV through use of a well-documented, reproducible methodology. Questions the study sought to answer were what was published, when and where was it published, and by whom. Though it would not be possible to provide definitive answers to all those questions, it was hoped the study would provide baseline information about the nature of scholarly publishing on ZIKV and Zika Virus Infection, as we know it now. In addition to being of interest to scholars and researchers, this information will assist librarians in making collection management decisions in support of ZIKV scholarship and research, and enhance the efforts of public services librarians who provide consultation and instruction in this subject area.

\section{Methods}

The parameters selected for this study included publication date, source journal, subject and category of source journal, country of first author, and publication type. The bulk of the data for the study was obtained from the PubMed database. Produced by the United States National Library of Medicine (NLM), PubMed is among the world's largest and most popular bibliographic databases for the scholarly and professional literature in biomedicine and the preclinical sciences. PubMed was selected for use in this study because, though primarily an English-language database, it includes articles published in many non-English languages. It also includes articles from journals not indexed for MEDLINE, and is freely available worldwide via the Internet. In addition to PubMed records, data for the 
study was obtained from the NLM Catalog and through manual review of the full text of selected journal articles.

The search strategy used for this study consisted of the words (Żika OR ZIKV) entered into the main PubMed search box, followed by execution of the search via PubMed's Automatic Term Mapping system. With Automatic Term Mapping, unqualified search terms are searched both as a keyword in all fields of the database record and under the Medical Subject Headings (MeSH headings) to which the terms are mapped. In this search, the term Zika mapped to the MeSH headings Zika Virus and Zika Virus Infection, both introduced to the MeSH thesaurus in early 2016. The concurrent keyword search served as a valuable adjunct because of its ability to retrieve new submissions that have not yet been indexed, as well as articles from journals that are not indexed for MEDLINE. The results were limited to articles with an Entrez Date (EDAT) range of 01/01/1952 through 12/31/2016, with EDAT defined as the date the citation was added to PubMed. In many cases, the EDAT precedes the publication date by several months.

The PubMed records were converted to the MEDLINE format, and imported into an EndNote library. In preparation for the import, the PubMed (NLM) import filter was modified to ensure that data elements would be inserted into the desired EndNote fields. The records were then exported into a Microsoft Excel spreadsheet, using a customized output style.

Once in Excel, the results were de-duped, and exclusions applied for off-topic articles, errata or corrections, and.articles from general interest publications. Off-topic articles were identified through manual review of the author, author address, investigator name, title, and abstract fields of the PubMed records. Many off-topic articles were incidental retrievals due to the occurrence of the word Zika as an author surname or as a component of an author email address. Errata or corrections were identified via the PubMed Publication Type (PT) field, or from the title or full-text of the article. Finally, as this study 


\section{Bibliometric Analysis of Zika literature}

was focused on the scholarly/professional literature, articles from general interest publications, such as Consumer Reports and Time, were excluded.

Once the study set was obtained, the results were sorted by publication date, divided into fiveyear increments. This enabled creation of a timeline of the growth of scientific publication on ZIKV. The results were then sorted alphabetically by the titles of the source journals in which the articles appeared. The total number of source journals was determined, as well as the number of articles published by each source journal. The journal list was sorted in descending order of the number of articles published, with the journal publishing the most articles listed at the top, followed by the journal that published the second most, and so on. Journals publishing the same number of articles were sorted secondarily by title from $A$ to $Z$.

The frequency-ranked journal list was divided into three equal sections based on the principles of Bradford's Law of Scattering, a tool developed for the analysis of journal productivity in a particular subject area (Bradford 1950, Andres 2009). According to this law, a frequency-ranked list of source journals publishing on a given subject can theoretically be divided into three groups or "zones", each of which contributes approximately one-third of the articles. The first and smallest group, referred to as Zone 1, represents those journals that are most productive and are therefore considered central to the discipline. The second group, Zone 2, includes a substantially larger group of journals that contributes the middle third of the articles. Though these journals publish less frequently on the topic compared to the first group, they are nevertheless considered important to the discipline. And finally, Zone 3 consists of a much larger group of journals, which together contributes the final one-third of the articles. The journals in Zone 3 only rarely publish articles on the subject, often only once or twice throughout the time frame of the study.

The subject of each source journal was obtained from the Broad Subject Term(s) field of the NLM Catalog record for that journal. As only one subject could be used for this analysis, when more than 
one subject was listed in the catalog record, the author made a choice following assessment of the journal content. When no Broad Subject Terms were listed for a given journal, MeSH headings were substituted. When neither was provided, the author determined the subject based on information from the journal's website. Each of the subject areas were subsequently assigned to one of four broad categories: Basic Science, Medicine/Nursing, Public Health/Epidemiology, and Other. The number of articles published in each subject and category was tallied, and the subjects and categories frequencyranked.

The country of the first author was obtained from the PubMed Author Address (AD) field. However, often only the city, state, or institution was listed, rather than the country name, requiring a manual determination. When more than one country was listed for a given author, only the first was used for this analysis. When no address information was provided by the PubMed record, the information was searched for in the full-text of the article. When no country information was available, it was recorded as "Unable to Determine". Articles written by the editor or editorial staff of a given journal without a stated country were recorded as "Unable to Determine". The total number of contributing countries was determined, and the list of countries was sorted in descending order of the number of articles contributed.

Finally, an analysis of the type of articles published on ZIKV was undertaken. Initially, it was hoped that this analysis could be conducted through use of the PubMed Publication Type (PT) field. However, in many of the records, the PT field was not populated. Furthermore, the terms used for this field lacked the granularity and specificity necessary for an accurate determination. A wide variety of articles, ranging from brief news items to lengthy research reports, were designated simply as "Journal Articles", while many articles designated as "News" by journal editors were not assigned the "News" search tag by PubMed. Consequently, categorization of the articles using the PT field was not feasible. 


\section{Bibliometric Analysis of Zika literature}

As an alternative, the author conducted a comparison of the number of opinion pieces versus the number of research articles for six infectious diseases: Chikungunya, Dengue, Ebola, Lyme, West Nile, and Zika. The aim was to paint a broad picture of the current research landscape for each of the diseases, under the premise that early in the course of an emerging disease, there would be a greater proportion of editorials and letters-to-the-editor relative to the number of primary research articles. With the passage of time, as more funds, personnel, and resources are directed toward the conduct of rigorous research on the disease, the balance would gradually shift. By comparing the current situation for ZIKV with that of other recently emerged infectious diseases, it was hoped that useful observations could be made.

PubMed searches were conducted for each of the six terms, with the term "West Nile" used in quotes. Filters for Letter, Comment, and Editorial were applied to each search, and the number of results noted. This represented the number of opinion pieces in the database for that topic. The filters were cleared, and filters for Clinical Trial, Meta-analysis, Multi-center Study, and Systematic Reviews were then applied. A search was also run on the exploded MeSH heading Epidemiologic studies, which included narrower terms such as cross-sectional studies, case control studies, and prospective and retrospective cohort studies. Combined, these provided a rough estimate of the number of research articles that had been published for each topic. It was now possible to make a comparison between the number of opinion pieces and research articles published on each of the six diseases. Though this method did not guarantee to pick up all articles in the respective categories, it did identify the majority of them, and the method's reproducibility will allow it to be used in future studies.

\section{Results}

The PubMed search was initially conducted on $05 / 09 / 2017$, and updated on $11 / 14 / 2017$. The update was conducted well after the end of calendar year 2016 so as to pick up any late submissions 


\section{Bibliometric Analysis of Zika literature}

that lacked the search terms in the PubMed record, but which were eventually assigned either the Zika Virus or Zika Virus Infection MeSH headings. Though a few records satisfying the search criteria may have been added to PubMed after 11/14/2017, their omission would have a negligible effect on the results. Upon limiting to EDAT $=01 / 01 / 1952-12 / 31 / 2016$, and application of exclusion criteria, a final set of 1961 results was obtained.

\section{< Fig. 1. PubMed records included in the study >}

Analysis of the publication date of the articles showed that 61 articles were published on ZIKV between 1952 and 2011, constituting 3.1\% of the total. Many of these included ZIKV in the context of a larger discussion of medically important arboviruses; only 10 of the 61 articles were primarily about ZIKV infections in humans. There was a minor increase in publishing activity between 1972 and 1986 due to several reports on yellow fever in various African countries, a yellow fever epizootic in the Zika Forest of Uganda in 1972, and several serological surveys of multiple arboviruses in Africa. One might be tempted to discount these articles as irrelevant, but it is useful to recall that ZIKV was discovered during a sylvatic yellow fever study in Uganda, emphasizing the close relationship between the two viruses. Another small increase in the number of publications occurred in the 2007-2011 period, boosted by the 2007 outbreak on Yap Island.

\section{< Table 1. Publication date of articles, in 5-year increments >}

At nearly $97 \%$ of the total, the $2012-2016$ period encompasses the $2013-2015$ outbreaks in French Polynesia and the Pacific Islands, as well as the widespread epidemic in the Americas of 20152016. But the trend had a sluggish beginning, with only 6 articles published in 2012, 3 in 2013, 27 in 2014, and 42 in 2015. Within the first three months of 2016, however, there was a greater than five-fold increase, from 31 articles in January 2016 to 157 articles in March 2016. At the time of this study, a total of 1822 articles had been published in 2016, a substantial proportion of which focused specifically on 
Bibliometric Analysis of Zika literature

ZIKV and/or the ongoing outbreak in the Americas. The mid-year dip in publications was possibly due to routinely scheduled publisher down-times in mid-summer.

< Fig. 2. Articles published between January 2015 and December 2016, by month >

When the journals were ranked by title according to the number of articles they published on ZIKV, it was found that the literature emanated from 593 unique journal titles. Of these, $14(2.4 \%)$ journals contributed twenty or more articles, and $38(6.4 \%)$ journals contributed ten or more. In contrast, 481 (81.1\%) contributed three or fewer articles; 435 (73.4\%) contributed one or two articles; and 327 (55.1\%) contributed only one article.

The frequency-ranked journal list was divided into the three Bradford zones, each of which contributed approximately one-third of the articles. With a total of 1961 articles in the study, Zone 1 consisted of 657 articles, Zone 2 of 653 articles, and Zone 3 of 651 articles, with the cut-off between Zone 2 and 3 occurring midway through the alphabetical list of journals contributing three articles.

The first zone consisted of 19 (3.2\%) journals, and included titles in medicine, science, infectious diseases, tropical medicine, microbiology, and epidemiology. The highest-ranking journal in Zone 1 contributed 81 articles and the lowest-ranking journal contributed 15 articles. The middle group, Zone 2, included 103 (17.4\%) journals, with the number of contributed articles ranging from 3 to 14 articles. The largest group, Zone 3, included 471 (79.4\%) journals, each if which contributed 3 or fewer articles.

< Table 2. Zone 1 journals, frequency-ranked $(\mathrm{N}=19)$ >

Analysis of the subject content of the source journals showed that they stemmed from 71 unique subject areas. Nearly every basic science discipline was represented on the list, as were most of the medical specialties. When the subjects were sorted according to frequency, journals in medicine were shown to have contributed the greatest number of articles at $374(19.1 \%)$, closely followed by communicable diseases at $369(18.8 \%)$ articles. Public health was a distant third with $158(8.1 \%)$ articles, followed by virology, science, microbiology, and tropical medicine. 
Bibliometric Analysis of Zika literature

\section{< Table 3. Top 20 subjects of source journals, sorted by frequency >}

When the subjects of the source journals were assigned to broad categories, Medicine/Nursing was found to be the most frequent category by a large margin, at 1,199 (61.1\%) articles. The Basic Science category claimed 536 (27.3\%) articles, followed by Public Health/Epidemiology with 188 (9.6\%) articles. The Other category, which included dentistry, veterinary medicine, physics, and other subjects, included $38(2.0 \%)$ articles.

The country of the first author was available from the PubMed record for 1,597 (81.4\%) of the articles. Of the remaining articles, the country information for $156(8.0 \%)$ articles was obtained by reviewing the full text, and for $208(10.6 \%)$ articles, the country could not be determined. Analysis of the participating countries revealed a widely dispersed, global effort, with articles emanating from 82 countries. Leading the list was the United States, followed by Brazil, the United Kingdom, China, and France. There were strong contributions from several western European countries, Colombia, India, Canada, Thailand, and Australia. However, just as articles on ZIKV were published in journals on a wide range of subjects, so too were they written by authors working out of locations around the globe.

$<$ Table 4. Country of first author (top 20) >

Finally, the searches to determine the number of opinion pieces versus research articles for the six infectious diseases were run in PubMed on 05/04/2017. The total number of articles retrieved for each disease varied widely, from a low of 2,733 for ZIKV to a high of 17,200 for Dengue, making evaluation of the percentages more useful than the raw figures.

At $16.7 \%$, the number of opinion pieces on ZIKV clearly exceeded the number of articles that fit the criteria used here for research articles, which came in at $2.9 \%$. However, these figures are difficult to interpret in isolation, making a comparison with other infectious diseases particularly useful. The two diseases with the highest percentages of opinion pieces were found to be Ebola and ZIKV, at $13.1 \%$ and $16.7 \%$ respectively. This can be contrasted with a low of $3.7 \%$ for West Nile, followed by $5.5 \%$ for 
Dengue. As for research articles, again Ebola and ZIKV were the standouts, with ZIKV ranking lowest at $2.9 \%$ and Ebola slightly higher at $3.9 \%$. In comparison, Lyme disease showed the highest percentage of research articles at $12.5 \%$, followed closely by Dengue at $11.3 \%$.

< Table 5. Comparison of "opinion pieces" versus "research articles" for six infectious diseases >

\section{Discussion}

At the end of 2016, the corpus of published journal literature on ZIKV was still relatively small, with fewer than 2000 articles in PubMed. With the massive 2015-2016 outbreak in the Americas, the scientific, medical, and global health communities, in partnership with the scholarly journal publishing enterprise, launched a remarkably timely and robust response to the emerging crisis. With the declaration on 02/01/2016 by the World Health Organization of a Public Health Emergency of International Concern (PHEIC), many journals instituted a shortened publication cycle to fast track manuscripts on ZIKV, helping to further accelerate the flow of knowledge (Albuquerque 2017).

An examination of the list of most productive journal titles of this study shows similarities and differences with the findings reported by Singh (Singh 2015) and Martins (Martins 2016). Whereas the Singh study's Zone 1 consisted of $6.8 \%$ (20/293) of the journal titles, the present study's Zone 1 consisted of $3.2 \%(19 / 593)$ of the journals. Though it is premature to infer much from this, it does suggest that the list of journals comprising Zone 1 may be becoming more consolidated. Four of the five most productive journals reported by Singh were included in Zone 1 in the present study, although their rankings in the list were different, usually lower. Similarly, eleven of the fourteen titles on Martins' list of most productive journals appeared in Zone 1 of the present study, though with differing rankings. The discrepancies between the present and previous studies may be due to differences in the databases used as the source of raw data, inclusion/exclusion criteria, sample sizes, and date ranges. It should be noted that the Singh and Martins studies were conducted much earlier in the course of the 2015-2016 


\section{Bibliometric Analysis of Zika literature}

ZIKV outbreak in the Americas. As the literature on ZIKV evolves, the list of most productive journals can be expected to experience continuous fluctuations.

Like the journals themselves, the subject areas of the journals reflected an extraordinarily broad range. Given the symptoms and complications of ZIKV infections, it was no surprise that neurology, allergy/immunology, pediatrics, nursing, gynecology/obstetrics, and ophthalmology all ranked in the top twenty subjects, along with general medicine and science. But even journals in specialty areas such as anesthesiology, psychiatry, gerontology, and oncology found aspects of this emerging infectious disease to be of interest to their reading audience. As a microcosm of the whole, the subjects of the nineteen Zone 1 journals reflected a high degree of interdisciplinary interest, including four prominent general medicine journals and two general science journals. At the category level, the relatively low percentage of articles published in Public Health/Epidemiology journals compared with Medicine/Nursing and Basic Science journals may be due to a reduced emphasis on scholarly publication among public health practitioners.

With contributions from scholars and clinicians working in over eighty countries, it is clear that efforts to combat ZIKV has become a worldwide endeavor. Since PubMed is a product of the United States National Library of Medicine, it was not unexpected that the top ranking country was the United States. PubMed is the preeminent bibliographic database for biomedical research in the US, and manuscripts resulting from US National Institutes of Health (NIH) grant-funded projects are required to be deposited into PubMed Central. That the second highest ranking country was Brazil is also no surprise, given that it was at the epicenter of the evolving epidemic. Since PubMed's coverage of nonEnglish publications is limited, it is likely that the scholarly output on ZIKV by countries outside the United States was substantially higher than was represented in PubMed.

The results of this study's country analysis differed considerably from those by MartinezPulgarin et al.(Martinez-Pulgarin et al. 2016), but correlated well with the study by Albuquerque et al. 
2

(Albuquerque et al. 2017), despite the latter's use of different databases as the source of raw data. The ranking of the top five countries in the present study exactly matched those of Albuquerque et al., and all but one of the top fifteen countries they listed were also in the top fifteen of the current study, although some of their positions shifted. Neither of the earlier studies described how the country information was determined.

Finally, the comparison of the number of opinion pieces versus primary research for the six infectious diseases provided a hint as to the current state of knowledge on these topics. It is notable that the two diseases with both the highest percentages of opinion pieces and the lowest percentages of research articles were Ebola and ZIKV. Despite their low strength-of-evidence, it is evident that for emerging diseases, publication types such as letters, brief communications, and case studies, are important tools for disseminating information as it becomes known. Follow-up studies using the method described herein will provide greater insight into the long-term trends of scholarly output on such diseases as the pace and progress of research accelerates.

\section{Limitations}

Since it drew its raw data from only one database, this study does not purport to be a comprehensive analysis of all published scholarship on ZIKV. Rather, it is an attempt to provide a description of the literature of ZIKV as it exists now, using the data found in PubMed as a representative sample. Owing to the scope and widespread availability of PubMed, it is likely that the study's findings provide a fairly accurate representation of the nature of formal scholarly publication on ZIKV. It must be noted that the sample size used in the study was relatively small, which forced an arbitrary cut-off between Zones 2 and 3 in the journal frequency list.

In addition, use of the country of the first author for the country analysis may have yielded an incomplete representation of each country's output by failing to take into account the international 


\section{Bibliometric Analysis of Zika literature}

collaborations that occurred, as evidenced by the large number of articles published by multiple authors, working out of multiple countries. Still, the decision as to who to list as first author is one that is not taken lightly by authors and collaborators, and therefore is felt to hold some significance. In addition, multiple countries were sometimes listed for the first author, or different countries were listed for a given author on multiple articles published at approximately the same time. Nevertheless, it was felt this method provided a sufficient approximation of the situation until such time as detailed author metrics can be performed.

\section{Conclusion}

As a snapshot of the published scholarly journal literature on ZIKV through calendar year 2016, this study provided convincing evidence that an emerging epidemic is a powerful catalyst for the generation of scientific knowledge. The number of articles published in the last year of the study was found to be over thirteen times greater than the number published in the preceding 64 years combined. The articles included in this study were published by nearly 600 journals, but fully one-third of the articles were published by fewer than twenty highly productive journals. Mirroring the breadth of journals publishing on the topic, scholarship on ZIKV emanated from researchers working around the globe, writing in journals that spanned dozens of disciplines.

The study's findings have important implications for students, faculty, researchers, and clinicians. Those wishing to remain abreast of the field of ZIKV research may wish to use the list of journals included in Zone 1 to guide their current awareness activities. More importantly, the ranked journal list in its entirety, along with the subject and country lists, serves as a clear reminder of the necessity for reading beyond one's favorite publications, even beyond one's own discipline, in order to discover the full range of scholarly literature on the topic. 


\section{Bibliometric Analysis of Zika literature}

Librarians working in academic, hospital, and special libraries, especially those involved in collection management, may also find the study useful. "Analysis of journal productivity [via Bradford's Law] has ... been used as a tool for collection management in libraries by identifying core journals in subject areas, thereby providing evidence for journal subscription decision making." (Wolfram 2003). The long-running Mapping the Literature of Allied Health project of the Medical Library Association, which produced 21 published papers between 1997 and 2016, listed collection management as one of the primary uses of the studies (Schloman 1997). In an era of tight budgets, the results of this study may help librarians estimate the importance of specific journal titles to patrons working in the area of ZIKV research, and thus can be used to guide purchasing, swapping, and/or cancellation decisions. Finally, research and instruction librarians can draw on the evidence provided by the long tail of the journal distribution to convey to their patrons and students the importance of conducting comprehensive literature searches across multiple databases.

Updates to the study are expected to show a rapidly expanding body of research on ZIKV, with continuously fluctuating journal and country productivity rankings, as well as a shift toward increased levels of rigorous research. For a more comprehensive analysis, the study could be expanded to incorporate data from additional databases, such as EMBASE, Google Scholar, LILACS, SciELO, Scopus, Web of Science, and others. A more granular look at author metrics, publication types, and institutional and country productivity would likewise provide additional insights. Finally, in this age of real-time communications, it would be useful to assess the continuing role of the formally published scholarly journal article in the dissemination of information during and following global health crises.

Having at last revealed its capacity to wreak havoc on mankind, ZIKV will no doubt continue to attract the interest of researchers and clinicians across the spectrum of biomedical disciplines, leaving in its wake an ever expanding body of literature waiting to be explored. 
Bibliometric Analysis of Zika literature

\section{References}

Albuquerque, P. C., M. J. Castro, J. Santos-Gandelman, A. C. Oliveira, J. M. Peralta, and M. L. Rodrigues. 2017. Bibliometric indicators of the Zika outbreak. PLoS Neglected Tropical Diseases 11 (1): e0005132. doi: 10.1371/journal.pntd.0005132.

Andres, A. 2009. Measuring academic research: how to undertake a bibliometric study. Oxford, UK: Chandos.

Bradford, S. C. 1950. Documentation. Washington, D. C.: Public Affairs Press.

Crawley-Low, J. 2006. Bibliometric analysis of the American Journal of Veterinary Research to produce a list of core veterinary medicine journals. Journal of the Medical Library Association 94 (4): 430-4.

Cruz-Calderon, S., K. M. Nasner-Posso, P. Alfaro-Toloza, A. E. Paniz-Mondolfi, A. J. Rodriguez-Morales. 2015. A bibliometric analysis of global Ebola research. Travel Medicine and Infectious Disease 13 (2): 202-4. doi: 10.1016/j.tmaid.2015.02.007.

Culquichicon, C., J. A. Cardona-Ospina, A. M. Patino-Barbosa, and A. J. Rodriguez-Morales. 2017. Bibliometric analysis of oropouche research: impact on the surveillance of emerging arboviruses in Latin America. F1000Research 6: 194. doi: 10.12688/f1000research.10936.2.

Davis, P. M. 2002. Where to spend our e-journal money? Defining a university library's core collection through citation analysis. portal: Libraries and the Academy 2 (1): 155-166.

Dick, G. W., S. F. Kitchen, and A. J. Haddow. 1952. Zika Virus. I. Isolations and serological specificity. Transactions of the Royal Society of Tropical Medicine and Hygiene 46 (5): 509-20.

Duffy, M. R., T. H. Chen, W. T. Hancọck, A. M. Powers, J. L. Kool, R. S. Lanciotti, M. Pretrick, M. Marfel, S. Holzbauer, C. Dubray, L. Guillaumot, A. Griggs, M. Bel, A: J. Lambert, J. Laven, O. Kosoy, A. Panella, B. J. Biggerstaff, M. Fischer, and E. B. Hayes. 2009. Zika Virus outbreak on Yap Island, Federated States of Micronesia. New England Journal of Medicine 360 (24): 2536-43. doi: 10.1056/NEJMoa0805715. 
Garg, K. C. and S. Kumar. 2017. Bibliometrics of global Ebola virus disease research as seen through Science Citation Index Expanded during 1987-2015. Travel Medicine and Infectious Disease 16: 64-65. doi: 10.1016/j.tmaid.2016.09.013.

Lascar, C. and L. D. Mendelsohn. 2001. An analysis of journal use by structural biologists with applications for journal collection development decisions. College \& Research Libraries 62 (5): 422-433.

Martinez-Pulgarin, D. F., W. F. Acevedo-Mendoza, J. A. Cardona-Ospina, A. J. Rodriguez-Morales, and A. E. Paniz-Mondolfi. 2016. A bibliometric analysis of global Zika research. Travel Medicine and Infectious Disease 14 (1): 55-7. doi: 10.1016/j.tmaid.2015.07.005.

Martins, M. F. M. 2016. Análise bibliométrica de artigos científicos sobre o vírus Zika. Revista Eletrônica de Comunicação Informação e Inovação em Saúde 1 (10): 1-9.

Musso, D., E. J. Nilles, and V. M. Cao-Lormeau. 2014. Rapid spread of emerging Zika virus in the Pacific area. Clinical Microbiology and infection 20 (10): 0595-6. doi: 10.1111/1469-0691.12707.

Oxford, John, Paul Kellam, and Leslie Collier. 2016. Human virology. 5th ed. Oxford, UK: Oxford University Press.

Pan American Health Organization (PAHO). Zika cumulative cases - 16 November 2017. Updated $11 / 16 / 2017$ http://www.paho.org/hq/index.php?option=com_content\&view=article\&id=12390\&ltemid=420 90\&lang=en.

Rethlefsen, M. L. and A. A. Livinski. 2013. Infectious diseases citation patterns: mapping the literature 2008-2010. Journal of the Medical Library Association 101 (1): 55-62. doi:10.3163/15365050.101.1.009.

Schloman, B. F. 1997. Mapping the literature of allied health: project overview. Bulletin of the Medical Library Association 85 (3): 271-77. 
Bibliometric Analysis of Zika literature

Singh, N. 2016. Scientometric analysis of research on Zika virus. Virusdisease 27 (3): 303-306. doi: 10.1007/s13337-016-0339-3.

Vasconcelos, P. F., and C. H. Calisher. 2016. Emergence of human arboviral diseases in the Americas, 2000-2016. Vector Borne and Zoonotic Diseases 16(5): 295-301. doi: 10.1089/vbz.2016.1952.

Vera-Polania, F. M. Munoz-Urbano, A. M. Banol-Giraldo, M. Jimenez-Rincon, S. Granados-Alvarez, and A. J. Rodriguez-Morales. 2015. Bibliometric assessment of scientific production of literature on Chikungunya. Journal of Infection and Public Health 8 (4): 386-8. doi: 10.1016/j.jiph.2015.03.006.

Waddell, L. A. and J. D. Greig. 2016. Scoping review of the Zika virus literature. PloS One 11 (5): e0156376. doi: 10.1371/journal.pone.0156376.

Wolfram, D. 2003. Applied informietrics for information retrieval research. Westport, CT: Libraries Unlimited.

Zhou, H., B. Eaton, Z. Hu, and B. Arif. 2016. Accidental discovery and isolation of Zika virus in Uganda and the relentless epidemiologist behind the investigations. Virologica Sinica 31 (4): 357-61. doi: 10.1007/s12250-016-3821-6.

Zyoud, S. H. 2016. Dengue research: a bibliometric analysis of worldwide and Arab publications during 1872-2015. Virology Journal 13: 78. doi: 10.1186/s12985-016-0534-2. 

Fig. 1. PubMed records included in the study

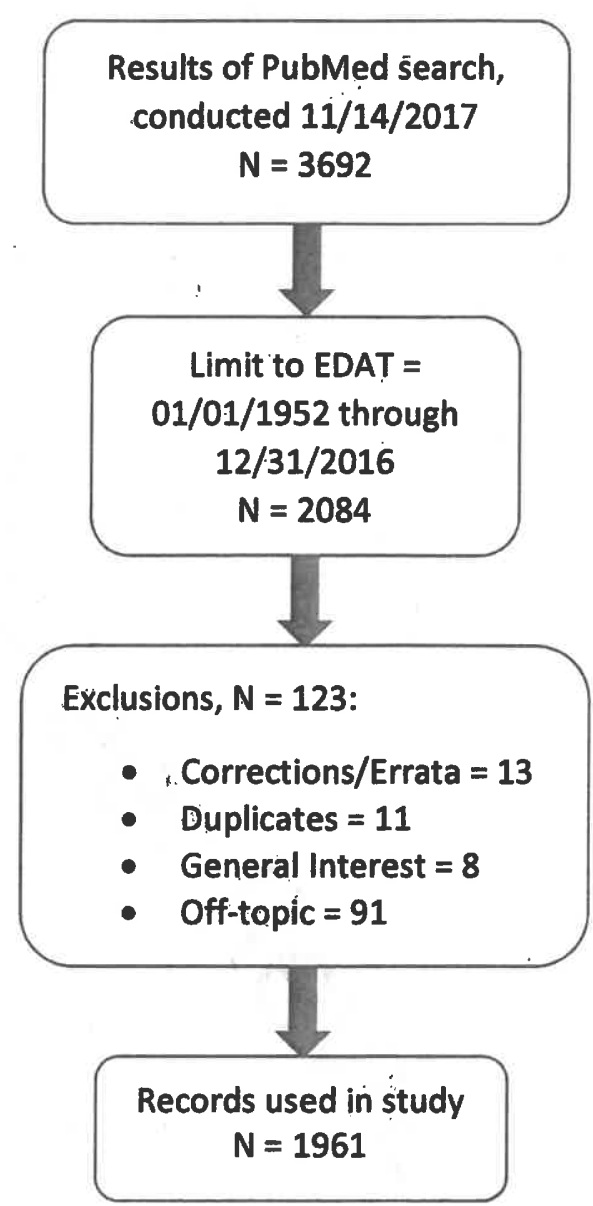



1

2 3. 4

5 6 7 8 9 10 11 12 13 14 15 16 17 18 19 20
Table 1. Publication date of articles, in 5-year increments

\begin{tabular}{|l|c|c|}
\hline Year range & \# articles & \% of total \\
\hline $1952-1956$ & 8 & 0.4 \\
\hline $1957-1961$ & 1 & 0.1 \\
\hline $1962-1966$ & 2 & 0.1 \\
\hline $1967-1971$ & 3 & 0.1 \\
\hline $1972-1976$ & 6 & 0.3 \\
\hline $1977-1981$ & 10 & 0.5 \\
\hline $1982-1986$ & 7 & 0.4 \\
\hline $1987-1991$ & 5 & 0.2 \\
\hline $1992-1996$ & 3 & 0.1 \\
\hline $1997-2001$ & 4 & 0.2 \\
\hline $2002-2006$ & 1 & 0.1 \\
\hline $2007-2011$ & 11 & 0.6 \\
\hline $2012-2016$ & 1900 & 96.9 \\
\hline TOTAL & 1961 & 100.0 \\
\hline
\end{tabular}


1

2 3
Fig. 2. Articles published between January 2015 and December 2016, by month.

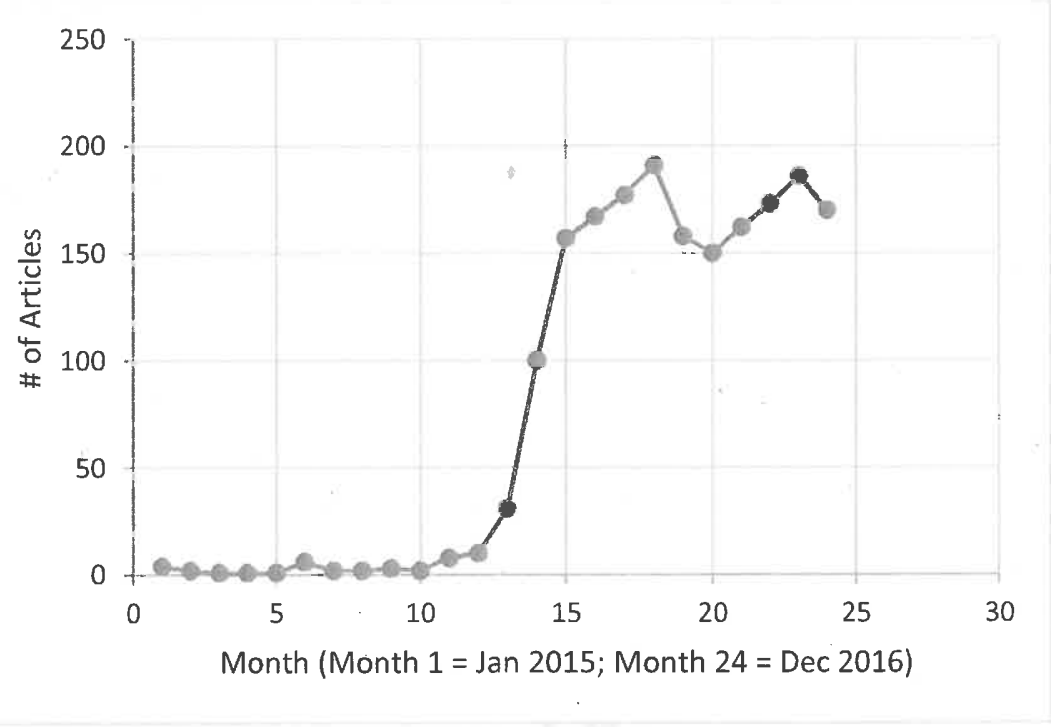


Table 2. Zone 1 journals, frequency-ranked ( $N=19$ )

\begin{tabular}{|c|l|c|}
\hline Rank & Journal & \# of articles \\
\hline 1 & BMJ & 81 \\
\hline 2 & PLoS Neglected Tropical Diseases & 59 \\
\hline 3 & Lancet & 57 \\
\hline 4 & Emerging Infectious Diseases & 56 \\
\hline 5 & MMWR. Morbidity and Mortality Weekly Report & 51 \\
\hline 6 & Euro Surveillance & 43 \\
\hline 7 & Lancet. Infectious Diseases & 41 \\
\hline 8 & Nature & 33 \\
\hline 9 & New England Journal of Medicine & 33 \\
\hline 10 & Science & 33 \\
\hline 11 & Travel Medicine and Infectious Disease & 26 \\
\hline 12 & JAMA & 22 \\
\hline 13 & American Journal of Tropical Medicine and Hygiene & 21 \\
\hline 14 & Cell Host \& Microbe & 20 \\
\hline 15 & International Journal of Infectious Diseases & 17 \\
\hline 16 & Scientific Reports & 17 \\
\hline 17 & Transactions of the Royal Society of Tropical Medicine and Hygiene & 17 \\
\hline 18 & Bulletin of the World Health Organization & 15 \\
\hline 19 & Clinical Infectious Diseases & 15 \\
\hline
\end{tabular}


1 2 3

Table 3. Top 20 subjects of source journals, sorted by frequency

\begin{tabular}{|c|l|c|l|}
\hline Rank & Subject & Number & Category \\
\hline 1 & Medicine & 374 & Medicine/Nursing \\
\hline 2 & Communicable Diseases & 369 & Medicine/Nursing \\
\hline 3 & Public Health & 158 & Public Health/Epidemiology \\
\hline 4 & Science & 91 & Basic Science \\
\hline 5 & Virology & 91 & Basic Science \\
\hline 6 & Microbiology & 83 & Basic Science \\
\hline 7 & Tropical Medicine & 81 & Medicine/Nursing \\
\hline 8 & Neurology & 56 & Medicine/Nursing \\
\hline 9 & Cell Biology & 43 & Basic Science \\
\hline 10 & Allergy and Immunology & 35 & Basic Science \\
\hline 11 & Nursing & 35 & Medicine/Nursing \\
\hline 12 & Pediatrics & 35 & Medicine/Nursing \\
\hline 13 & Gynecology and Obstetrics & 33 & Medicine/Nursing \\
\hline 14 & Reproductive Medicine & 32 & Medicine/Nursing \\
\hline 15 & Biology & 29 & Basic Science \\
\hline 16 & Biomedical Research & 27 & Basic Science \\
\hline 17 & Molecular Biology & 21 & Basic Science \\
\hline 18 & Biochemistry & 20 & Basic Science \\
\hline 19 & Ophthalmology & 20 & Medicine/Nursing \\
\hline 20 & Epidemiology & 18 & Public Health/Epidemiology \\
\hline
\end{tabular}


Table 4. Country of first author (top 20)*

\begin{tabular}{|l|l|c|}
\hline Rank & Country & \# references \\
\hline 1 & USA & 629 \\
\hline 2 & Brazil & 236 \\
\hline 3 & UK & 98 \\
\hline 4 & China & 95 \\
\hline 5 & France & 85 \\
\hline 6 & Italy & 49 \\
\hline 7 & Colombia & 42 \\
\hline 8 & India & 41 \\
\hline 9 & Canada & 41 \\
\hline 10 & Thailand & 36 \\
\hline 11 & Spain & 30 \\
\hline 12 & Germany & 28 \\
\hline 13 & Australia & 27 \\
\hline 14 & Switzerland & 27 \\
\hline 15 & French Polynesia & 26 \\
\hline 16 & Singapore & 26 \\
\hline 17 & Mexico & 18 \\
\hline 18 & Pakistan & 15 \\
\hline 19 & Netherlands & 14 \\
\hline 20 & Japan & 10 \\
\hline
\end{tabular}

* Excludes 208 articles for which the country not be determined 
1 2 3 4 5

Table 5. Comparison of "opinion pieces" versus "research articles" for six infectious diseases

\begin{tabular}{|c|c|c|c|c|c|c|c|}
\hline & 1 & 2 & 3 & 4 & 5 & 6 & 7 \\
\hline Search Term & $\begin{array}{l}\text { Comments, } \\
\text { Editorials, } \\
\text { and Letters } \\
\text { (\#) }\end{array}$ & $\begin{array}{l}\text { Comments, } \\
\text { Editorials, } \\
\text { and Letters } \\
(\%)\end{array}$ & $\begin{array}{l}\text { Clinical Trial, } \\
\text { Meta-analysis, } \\
\text { Multicenter } \\
\text { Study, and } \\
\text { Systematic } \\
\text { Reviews (\#) }\end{array}$ & $\begin{array}{l}\text { Epidemiologic } \\
\text { Studies (\#) }\end{array}$ & $\begin{array}{l}\text { Sum of } \\
\text { results } \\
\text { from } \\
\text { columns } \\
3 \text { and } 4\end{array}$ & $\begin{array}{l}\% \text { of } \\
\text { results } \\
\text { from } \\
\text { columns } \\
3 \text { and } 4\end{array}$ & TOTAL \\
\hline Chikungunya & 252 & 7.4 & 51 & 226 & 277 & 8.2 & 3399 \\
\hline Dengue & 951 & 5.5 & 439 & 1512 & 1951 & 11.3 & 17200 \\
\hline Ebola & 852 & 13.1 & 104 & 148 & 252 & 3.9 & 6418 \\
\hline Lyme & 1230 & 9.9 & 326 & 1229 & 1555 & 12.5 & 12431 \\
\hline "West Nile" & 256 & 3.7 & 89 & 523 & 612 & 8.8 & 6958 \\
\hline Zika & 457 & 16.7 & 34 & 45 & 79 & 2.9 & 2733 \\
\hline
\end{tabular}

Column:

1. Number of records retrieved when PubMed filters for Comment, Editorial, and Letter applied to search term.

2. Percent of records retrieved when PubMed filters for Comment, Editorial, and Letter applied to search term.

3. Number of records retrieved when PubMed filters for Clinical Trial, Meta-analysis, Multicenter Study, and Systematic Review applied to search term.

4. Number of records retrieved when search run in PubMed on (search term) AND exp Epidemiologic Studies[MeSH]

5. Sum of columns 3 and 4 .

6. Percent of Clinical Trial, Meta-analysis, Multicenter Study, Systematic Review, and Epidemiologic Studies.

7. Total number of results retrieved when PubMed search ran on the search term. Searches conducted 05/04/2017. 